\title{
Curriculum Shift: Innovative Teaching and Learning through STEM Initiatives
}

\author{
Kimberly Barcelona* \\ Winthrop Elementary School, New London Public Schools, New London CT, United States of America \\ *Corresponding author: kimbobkizzy@sbcglobal.net
}

Received August 27, 2013; Revised October 23, 2014; Accepted October 29, 2014

\begin{abstract}
Today, we live in an ever-changing global society. The task of schools continues to go through changes that must help students analyze situations, problem solve, and make informed decisions. The basic goal and purpose of education has changed dramatically, as has the complexity of the learning task. Economic needs in our global workforce require that schools prepare students with more than the basic memorization of facts. Students must have the ability to understand numerous variables and process data in efficient and effective ways. In order to meet the needs of $21^{\text {st }}$ century learners, the New London Public School system in Connecticut adopted new ways of thinking about the structure of its schools. This paper discusses how the New London Public School system as changed the traditional views of school structure and the process necessary to achieve innovative teaching institutions.
\end{abstract}

Keywords: STEM education, school restructuring, district magnet, curriculum reform

Cite This Article: Kimberly Barcelona, "Curriculum Shift: Innovative Teaching and Learning through STEM Initiatives.” American Journal of Educational Research, vol. 2, no. 10 (2014): 970-974. doi: 10.12691/education2-10-18.

\section{Introduction}

In order to provide a clear view of the changes the New London Public School district has adapted to, it is important to identify where the schools were before curriculum reform began in 2007. Under the State Department's accountability system, each Connecticut school is classified under six categories: Excelling;
Progressing; Transitioning; Review; Focus; and Turnaround. These classifications are used to mark school performance levels and track student achievement. (Table 1) A School Performance Index" (SPI) is calculated by averaging a given school's entire valid and non-excluded Student individual performance index (DPI). "A District Performance Index” (DPI) is calculated by averaging all of a given district's valid and non-excluded Student IPIs.

Table 1.

Understanding School Classifications

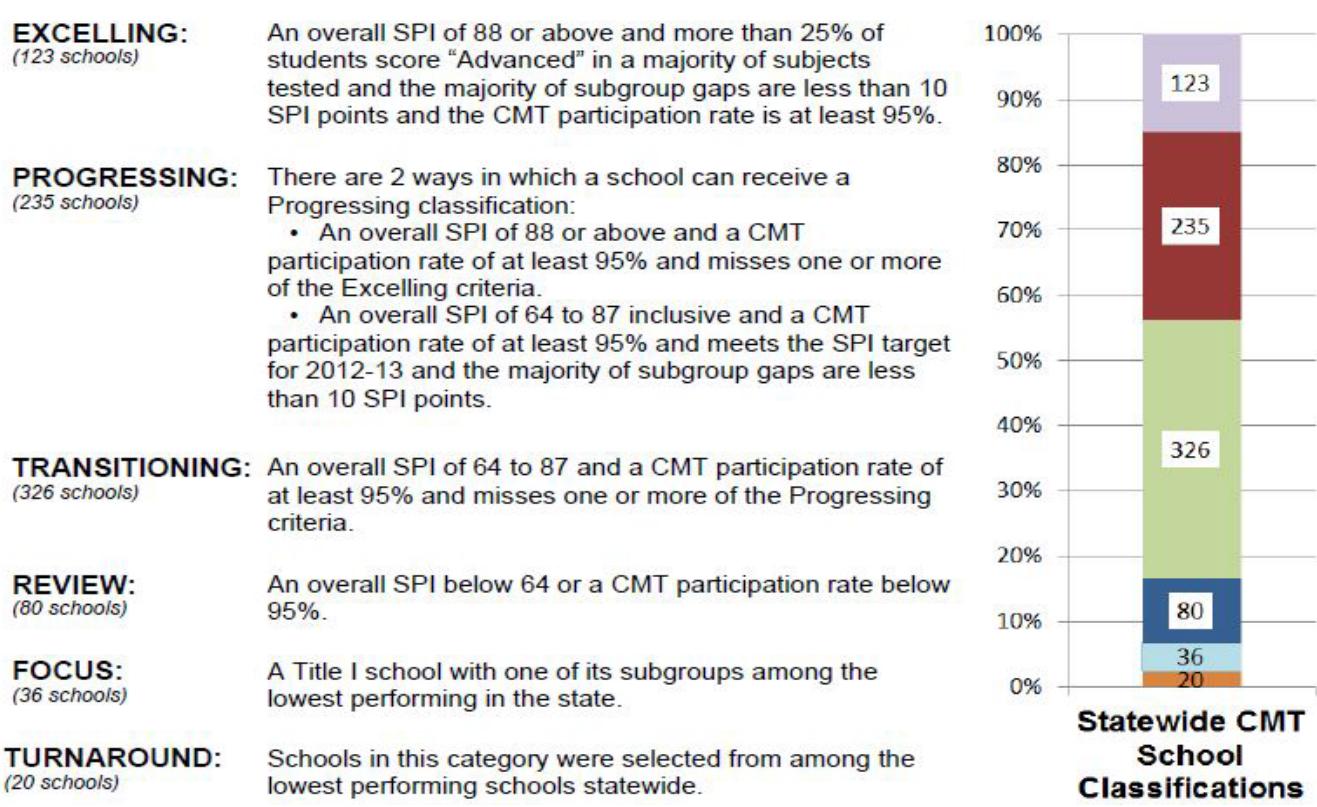

Table is from the State Department of Education: http://www.csde.state.ct.us/public/performancereports/20122013reports.asp 
In 2006, performance ratings for Winthrop Elementary School indicated it did not make adequate yearly progress (AYP) and had a DPI below 36. Schools that did not make AYP were placed on a "turnaround" status which, in layman's terms, meant the school was in trouble. It was common to hear in staff meetings that the school district was on the verge of a state take-over. Those statements by our administration were foreign and scary to the staff and many teachers and support staff did not even realize what that meant. This was the catalyst that gave rise to some needed change that would help the district give rise to some leaders who were paramount in organizing and presenting change efforts in curriculum. Kotter (1996) identifies the first stage in the change process as establishing a sense of urgency and this was the potential crisis that gave momentum to change efforts.

\section{Response to Needed Change}

In the following year the New London Public School district was assigned state consults to meet with each school and assist with a plan of action that was a bureaucratic system at work. This plan brought new initiatives to the district and affected the school, staff, students, and individual staff member. In the 2006-2007 school year the staff began to learn about changes that were already in progress and the principal and state consultant would meet with the staff weekly to provide everyone with the information that was necessary to make effective changes. The state consultant for Winthrop Elementary School began with an open forum discussion about the need for improvements in STEM education to move America's students to the top of the pack by enabling all students to learn deeply and think critically in science and math. From this initial discussion the staff learned that the entire school district was completely restructuring every school and Winthrop Elementary School was adopting a STEM focus of instruction. All stakeholders in the New London Public Schools were publically informed that each school would be renovated and designed to have a unique focus of instruction. The district was designated by state legislation as a "Magnet District" in Connecticut. Each school would have a focused theme to be offered including; STEM (Science, Technology, Engineering, Mathematics), Performing and Visual Arts, Dual Language and FLES (Foreign Language in Elementary Schools), and Leadership and Public Service (LAPS). Now that the change has become rooted, New London Public Schools operate four magnet schools; one intra-district elementary for New London students only, three inter-district elementary schools open to all Connecticut residents, and one inter-district magnet high school. Winthrop Elementary School was chosen as the STEM magnet school and our focus was to develop and implement a K-5 magnet school pathway program in Science, Technology, Engineering and Math (STEM). The STEM magnet school was also to begin building partnerships with the United States Coast Guard Academy, Connecticut College, Mitchell College, Mystic Aquarium, Denison Pequotsepos Nature Center, Mystic Seaport, Connecticut Science Center, Boston Museum of Science, and the Science and Technology Magnet High School of Southeastern Connecticut. The news about this huge change was overwhelming and a lot for everyone involved to absorb. At first, reactions were sharp- tongued with resentment but, as the change began to unfold, teachers began to see the opportunities it would provide for the students.

The phases of change that brought New London Public Schools to this point were scary, frustrating, confusing and utterly exhausting. The entire school was displaced mid-year into portable classrooms while our school was being renovated. This meant working over the holiday vacation was necessary and many involved changed plans in order to pack classrooms and unpack in the new location. Every staff member brought family and friends to help and even Coast Guard Academy students came to support the efforts. Although this might seem like it would have huge resistance from teachers, the process went smoothly and everyone supported those that needed extra help. The staff encouraged each other to remain focused on the need for a better education for our students and in times of tears teachers leaned on each other. The principal was also a true leader that helped lug and tug boxes and kept an open line of communication about what lie ahead for our staff. After the move, the conversations began immediately about the new STEM curriculum and imminent training that would be necessary for all those at the school. In addition, there were negotiations going on with the Teacher's Union and each teacher would have to apply to the magnet school they wanted to teach in. Teachers filled out paper work that included an essay of why we wanted to teach at that particular school and provided the district office with our three ranked choices of where we wanted to teach as the schools began reopening as new district magnet schools. At the time only the Dual Language School and the STEM school were in progress but teachers made a choice knowing that the other district magnet schools were to follow. The Teacher's Union remained involved in the change process; however, it was apparent that most of the teachers just accepted the change and waited for their assignment to where they would be teaching as the magnet schools began opening.

Next, the teachers got a letter that stated where we were placed to teach and this is when teachers became upset and frustrated with the system. Some teachers did not get their first choice and had to wait till the following year to reapply for the school they wanted to teach in. For example, if your interests were in the sciences and math, you would apply to teach in the STEM school and hope to be chosen. With this change came extra commitments that teachers had to agree in order to teach in that school. We had to participate in a two week training in the summer and agree to working extra duty hours throughout the school year. This time was paid at a higher hourly rate than each individuals personal contract salary step. The school's climate and culture was supportive, dedicated and caring. This made it less painful to have to go through the difficult changes and learning process. The leadership remained strong and, in turn, promoteda collaborative effort that became crucial for our success as a staff to embrace the changes we were facing.

The timeline continued and the school moved into portable classrooms while renovations began to build our STEM school. In March of 2007, the staff began looking at curriculum development in our Professional Learning Committees that focused on STEM education. At the same time, if it were not enough, we were still adjusting to, and 
learning about Common Core. It was an overwhelming amount of change but luckily our leaders helped break up each task into manageable parts and guided us at a tolerable pace. Our commitment to five extra days added on to the school year for professional learning was actually very successful to build staff morale. This allowed us to come together to discuss and envision what our school would look like as a STEM magnet school. The staff was always told that our voice was important and we were reminded about the importance of team effort and that a one hundred percent buy in was necessary. Of course we were also reminded that we were blessed to have a job in these hard economic times as incentive to "buy in". On a serious note, it was the presentation of the change that was successful to build a united front to make the change happen. We had time to come together as a staff, uninterrupted by students, and have those open conversations to share excitement and frustrations at the same time. The stage of creating a guiding coalition and getting the staff to work together was beginning to take shape which would lead to development of a vision and strategies for achieving that vision (Kotter, 1996, p.23). We were getting a new building with science labs, Lego labs, outdoor classrooms, a farm, recycling center, compost machines (worms included) and partnerships with the communities that were so valuable. There were so many wonderful things to look forward to that the list could go on. We all began to forget about the low socioeconomic status of our students and the difficulties our children faced outside of our classrooms and began to focus on what we can do for them while they are in our care. The statistical background about our school system and the population of Winthrop Elementary School was as follows:

Winthrop School Enrollment (2011)

Total Enrollment - 316

Rank Nationally - 36795 out of 53599

Rank in Connecticut - 493 out of 668

Winthrop School Students by Grade

1 st -52

2nd -55

3rd -59

4 th -54

5 th -50

6 th - 0

\section{Winthrop School Students by Gender}

Male - 182 (58\%)

Female - 134 (42\%)

Winthrop School Students by Ethnicity

American Indian - 1 (0\%)

Asian - 11 (3\%)

Black - 67 (21\%)

Hispanic - 199 (63\%)

White - 38 (12\%)

Winthrop School Student to Teacher Statistics

Pupil/Teacher Ratio: 12.4

Student/Teacher Rank in CT: 125 of 668

Full Time Teachers: 25.4

Rank in Connecticut: 423 of 668

Winthrop School Students by Lunch Assistance

Free Lunch Eligible - 236 (75\%)

Reduced-Price Lunch Eligible - 17 (5\%)

Combined Free or Reduced - 253 (80\%)

Rank in Connecticut: 130 of 668

Grade 5 (2011)

$\%$ at or Above Goal

Reading 28.3

Writing $\quad 38.4$

Mathematics $\quad 43.4$

Science 25.8

$\%$ at or above Proficient

45.2

77.7

71.7

The changes initiated at Winthrop Elementary School were initially developed and implemented in a "top-down" management style. Directions, guidelines, information, and plans came from the top administrators of our district but then that information was successfully shared and expectations were clearly communicated to our school staff. The process of change began with a bureaucratic approach that included many of the mechanisms identified by Owens and Valesky (2011). At first, the change efforts being made by the administration controlled and coordinated the behavior of the staff members in our schools which had relevance to the five mechanisms. Owens and Valesky emphasize the following five mechanisms:

- Maintain firm hierarchical control of authority and close supervision of those in the lower ranks.

- Establish and maintain adequate vertical communication.

- Develop clear written rules and procedures to set standards and guide actions.

- Promulgate clear plans and schedules for participants to follow.

- Add supervisory and administrative positions to the hierarchy of the organization as necessary to meet problems that arise from changing conditions confronted by the organization (Owens \& Valesky, 2011, p. 15).

It is a fact that the reform efforts were rooted in these principles, however, non-bureaucratic approaches and theories, such as the Human Resource Development Theory, began to take rise. An emphasis was given on "developing a culture in the organization that harnesses the conscious thinking of individual persons about what they are doing as a means of involving their commitment, abilities, and energies in achieving the goals of the organization (Owens \& Valesky, 2011, p. 17). The direction our school was going was paved for us by the authorities in places higher up the chain. Once the larger changes were in place, our staff was given some autonomy to develop strategies and plans necessary for enriching our curriculum in the areas of science, technology, engineering and math. We had to maintain integrity with the adopted common core standards for learning but we had to look at the areas that were not well defined, such as the sciences and technology areas. We had to look at the tools and resources available to us and refine how we were using them as well as create a plan to integrate the newly adopted "Engineering is Elementary" program brought to our district from the Boston Museum of Science Educational Department. Our job as a staff was large but the outcomes were well worth the dedication. Our principal and supervisor of curriculum and development worked together to create a plan for the staff that was broken down into tasks that were tackled in our staff meetings and during our professional learning communities. Kotter's stage to "communicate the vision" had to be constant. The guiding coalition was a role model for the staff to demonstrate expected behaviors of employees. The leadership naturally flowed into "empowering broad- 
based actions" to get rid of obstacles, which in this case was the tightly clutched traditional methods of teaching (Kotter, 1996, p. 87-119). Teachers were able to develop and review curriculum that would engage our students in activities promoting STEM education. These fields provide an approach of real-world, problem-based learning that students can apply in their lives, future learning, and careers. The staff quickly began to develop a vision of our school with hands-on, project-based activities, adventure learning, and engaging lessons. The great thing about developing curriculum for STEM is that the subjects can be integrated together for cohesive teaching and learning. This area of education is full of new ideas, innovation, and excitement. Our staff focused on encouraging critical thinking and real-world application skills. This would help students make connections between what they learn in school and what they see in our communities and in the world. By giving teachers a voice in the direction for change, the school was able to follow a well-laid out path that had been paved by the administration. It was evident that the majority of the teachers were on board with making the changes in our teaching practices to support STEM education. We all knew we had a lot of learning to do but as we began our professional development we quickly realized that we were actually participating in the activities the students would engage in and it was fun. Our leaders in the training process let us learn by doing, just like we would do with our own students. The extra professional development days turned out to be enjoyable and overall consensus was that it was worth the time invested. Opportunities allowing the staff to come together to participate in training is what Kotter identifies as being important to empower employees and give them the skills and attitudes to successfully become part of the change reform (Kotter, 1996, p. 119).

In December of 2008, we had another challenge that required us to again move mid-year into our new building. Although we all felt completely exhausted and stretched to the limits with packing and moving again, it was much easier this time as the mandate to streamline our collection of teacher "stuff" on the first move made our load a lot less.

Now it was time to put our game plan into effect and even though we expected sharp turns in the road. We knew we could only improve with effort. The students entered our new school with awe on their faces and excitement in their eyes. This, by itself, was even more motivation for the staff to keep up the momentum and begin our STEM educational focuses. Immediately shortterm wins were evident, which Kotter (1996) identifies as the sixth stage in the change process. The changes that were occurring brought teachers out of their classrooms and working with other teachers to work collaboratively on lesson development and implementation. We began sharing resources and ideas routinely and it became common practice to co-teach in the green house, the outside classrooms and down at the Long Island Sound shore line which was right in our backyard. It might sound as if the situation were "sink or swim" however, in reality the staff began to pull together to identify what strengths each of us had in certain curricular areas, allowing us to pull our efforts together to create a well-balanced delivery of instruction. The overall morale of the teachers improved as we began remembering the joy of teaching and why we chose the profession.

The partnerships that began to emerge with the community around us opened up opportunities that the students could, not only learn from, but remember for a lifetime. In 2010 President Obama spoke at the Coast Guard Academy graduation and our fifth grade class was able to attend the ceremonies. The Academy shares a common property line with us and our students are able to walk to the facilities there and attend learning experiences outside of the classroom. The opportunities for life experiences are as awarding for the students as they are for the teachers. Teachers naturally modeled excitement for learning, through the opportunities given to the school community, and the students built social science skills from the natural exchange of interaction with the teachers. The quality of education was improving from the process of change, as difficult as we know change can be. Teachers that were unwilling to change and resisted with full throttle were quickly silenced and negative behaviors were not reinforced and gradually disappeared. Our principal reminded us often to "stick with the cheerleaders that put energies into the excitement of the game and ignore those that focused on unfair calls from the referees".

The challenges that continue to face teachers are the advancements in technology with improvements being made to our SMART technology but professional development and support in these areas are provided for teachers wanting more assistance. It is in this situation that the bureaucratic mechanisms help to support teachers as our district added "supervisory and administrative positions to the hierarchy of the organization as necessary to meet problems that arise from changing conditions confronted by the organization” (Owens \& Valesky, 2011, p. 15). This can also be connected to Kotter's seventh stage in the change process which is to consolidate gains and produce more change (p. 23). Supervisory positions were added to promote and support proper implementation of new technology, in which the teachers needed direction and support. Technology development and implementation in schools has become a priority and Tim Holt clearly made a valid point when he wrote "Great technology should be at the point of instruction and be as accessible in learning as a pencil” (Dangerously Irrelevant, 2014).

Finally the final stage of Kotter's change process, anchoring new approaches in the culture, can be identified with higher achieving student performance and being able to articulate the connections between new behaviors and organizational success (p. 163). Although some assessment of success is subjective and not found in data scores and percentiles, it is important to evaluate the engaged learning behaviors of students and the love for learning that can be demonstrated through action. Data scores remain important; however, it is important to look at the whole picture and allow time for the change to become rooted. Kotter writes, "When new practices made in a transformation effort are not compatible with the relevant cultures, they will always be subject to regression” (Kotter, 1996, p. 157). Changes can come undone and it is vital to allow time and practice to firmly anchor what has been implemented. Recent data about our school demonstrates improvement and since the 2009-10 school year, our District Improvement Index (DPI) on the CMT has improved by 3.8 points to 61.4. Our DPI performance on 
the CAPT has improved from the 2009-10 school year by 5.5 points to 51.4. The school has advanced two classification stages and currently is in review status. Change continues to happen and in our fast-moving world and schools must keep the pace to allow students access to a relevant and essential education.

\section{Conclusion}

Communities, school leaders and teaching staff are aware of the need for the restructuring of schools; however, it continues to be unclear about how to approach the problem. What is not recognized is the impact these changes will have on the roles of educators, leaders, and policy makers. Schools must explore new organizational school settings that work to meet the needs of todays' learners. Many school systems recognize the need for organizational change and renewal that will allow students to be problem solvers and independent life-long learners. This paper shares a positive outcome for the inner-city district of New London, Connecticut. Together, school leaders and staff took a stand to face the change process and restructure their schools. Widespread organizational change proved to be successful at Winthrop Elementary School with the optimistic view that continuous growth is the outcome. Schools must avoid falling victim to the practice of ignoring the need for change and transformation. Change must occur if schools are to achieve their goals to prepare all learners for an everchanging global society.

\section{References}

[1] Holt, T. (2014). Dangerously Irrelevant. http://www.dangerouslyirrelevant.org

[2] Kotter, J. P. (1996). Leading Change. Boston, Mass.: Harvard Business Review Press.

[3] Owens, R.G., \& Valesky, T.C. (2011). Organizational Behavior in Education: Leadership and School Reform. (10 ${ }^{\text {th }}$ edition). Upper Saddle River, New Jersey: Pearson Education, Inc.

[4] State of Connecticut Department of Education. (2013). 165 Capitol Avenue, Hartford, CT.

[5] State of Connecticut. (2013). Connecticut 2012-2013 School Classification. Hartford, CT. 